My Dear Editor,

I received the copy of Indian Journal of Otolaryngology and Head \& Neck Surgery Vol : 50 No. 4/1998 dated : Oct-Dec. I am very glad late Dr. Karnik's photograph appears on the front page. He was great ENT Specialist and a dedicated person. During his tenure as Head of the Deptt. at K. E. M. Hospital, the department achieved lot of progress.

\author{
With Warm Regards, \\ Yours sincerely \\ Dr. L. H. Hiranandani
}

\title{
Editor's Reply
}

I am much encouraged to receive your letter dated December 21,1998 and most happy to note that you have liked to see the photograph of Prof. P. P. Karnik on the front page of IJOL (Vol $50 \mathrm{~N}: 4$ 1998) unfortunately I have missed him for ever in the tenure of my editorship. He was always a source of inspiration for better journal making.

By bringing his photograph on the cover page I wanted to creat a precedance. I hope our future editors of the journal shall follow this idea.

I believe this is the only way by which we can show our ultimate respect to such persons who dedicated themselves for the upliftment of our Association.

\section{Request for Printing E-Mail Address}

Compliments for an excellent presentation of the Indian Journal of Otolaryngology. I have a small suggestion. If you can print the e-mail addresses of all the stalwarts in our field, both Indian and international, it would be very useful for people like me to communicate with them and ask them about some problems that I face in my surgery or discuss some difficult case with them on the internet, provided of course that they would be willing to spend some of their valuable time for the same. In this era of internet, it would go a long way towards helping younger colleagues to upgrade their knowledge and be guided by experienced people.

Yours sincerely,

Arun P Behere

Nashik Road 422101 